\title{
25 Research Suare \\ The role of ZFP36 in Vitamin D receptor degradation
}

\author{
Xiangyu Wang \\ Xuejun Ge \\ Wang Liao \\ Yong Cao \\ Ran Li \\ Fang Zhang \\ Bin Zhao \\ Jie Du
}

\section{Video Byte}

Keywords: Cell Communication and Signaling, Vitamin D receptor, zinc finger protein 36, oral lichen planus, inflammatory bowel disease, Y box-binding protein 1, YBX-1, ZFP36

Posted Date: October 13th, 2021

DOI: https://doi.org/10.21203/rs.3.rs-966275/v1

License: (c) (i) This work is licensed under a Creative Commons Attribution 4.0 International License. Read Full License 


\section{Abstract}

Our epithelial cells provide a barrier to protect us from external hazards, but inflammatory diseases like oral lichen planus (OLP) or inflammatory bowel disease (IBD) weaken that protective barrier. Vitamin D receptor (VDR) mediates response to Vitamin D and may have inflammation-suppressing abilities. Deficiency in this nuclear hormone receptor has been associated with some inflammatory diseases like IBD. New research examined the behavior of VDR in oral and colonic epithelial cells under inflammatory conditions. The results showed that mRNA degradation, not interrupted transcription or protein instability, drove decreased VDR expression. Further experiments revealed that zinc finger protein 36 (ZFP36) mediated this degradation by binding to the untranslated end of VDR mRNA. Researchers also found evidence that VDR binds to YBX-1 (Y box-binding protein 1) blocking the translocation of YBX-1 to the nucleus, where it would activate inflammation and programmed cell death. These results suggest that the VDR decrease in oral and colonic epithelial cells under inflammatory conditions is due to ZFP36-induced mRNA instability and that VDR deficiency leads to cell death by releasing YBX-1 into the nucleus. With more research, addressing mRNA stability may present a unique therapeutic target for diseases like IBD and OLP. 